\title{
Descompasso entre saúde e arte: uma análise do perfil clínico ocupacional dos profissionais da música
}

\author{
Emerson de Araújo Nunes, Ronise Lima Costa, Renan Alves Resende, Fabiane Ferreira Ribeiro, \\ Rosana Ferreira Sampaio
}

\begin{abstract}
Resumo
Músicos apresentam risco aumentado de desenvolver sintomas associados a disfunções do sistema musculoesquelético como dor, fraqueza, dormência, cansaço e outros. Esses sintomas podem estar associados à técnica utilizada para tocar determinado instrumento, tempo de estudo, quantidade e duração dos intervalos, fatores geradores de estresse relacionados ou não à atividade musical, entre outros. A ocorrência de tais sintomas pode impactar negativamente a performance do músico, e até mesmo resultar em afastamento de suas atividades laborais. É importante (re) conhecer os sintomas e os fatores de risco para doenças musculoesqueléticas neste grupo a fim de se desenvolver e implementar estratégias preventivas. Neste contexto, foi criado no Serviço Especializado em Saúde do Trabalhador (SEST) do Hospital das Clínicas da UFMG um programa de atenção integral à saúde do músico. Realizar uma análise descritiva do perfil sócio demográfico, clínico e ocupacional dos músicos que participaram do programa de saúde do músico do SEST. Estudo transversal realizado no período de novembro de 2008 a junho de 2016. Para a coleta de dados, foi aplicado um questionário estruturado durante o acolhimento dos músicos no SEST, o qual é dividido em informações ocupacionais, clínicas e funcionais. Para avaliação da dor, foi usada a versão adaptada para o português do questionário Brief Pain Inventory. Os dados foram analisados utilizando o software SPSS versão 17. Foram avaliados 132 músicos (65\% do sexo masculino) com média de idade de 36 anos $(\mathrm{DP}=13,2)$. A maioria $(92 \%)$ relatou ser instrumentista, sendo mais frequente os instrumentistas de cordas, em sua maioria violonistas $(15,9 \%)$. Grande parte da amostra estava vinculada a alguma instituição oficial (73\%), sendo 36\% como aluno e $46 \%$ como profissional. O tempo médio de experiência foi 16 anos $(\mathrm{DP}=11,4)$. Sessenta e oito por cento dos músicos realizava estudos regulares, com duração média de 3,5 horas/dia. Em relação a queixas funcionais, $89 \%$ apresentou algum tipo de dor, $36 \%$ cansaço e $22 \%$ fraqueza. A região mais acometida foi o ombro direito (15\%), seguida por coluna cervical (13\%) e mão direita (9\%). Em uma escala de 0 a 10, a dor apresentou média 4 de interferência na atividade ocupacional desses músicos, sendo a média da intensidade de dor relatada igual a 3,6. A prevalência de queixas é semelhante à encontrada na literatura mundial. A experiência do SEST/HC/UFMG tem mostrado que há uma demanda crescente por atendimento no setor público deste grupo de trabalhadores. Conhecer o perfil clínico-ocupacional dos participantes do programa de atenção integral a saúde do músico poderá auxiliar os profissionais de saúde e da música a incorporar estratégias que possam contribuir para a prevenção da ocorrência de disfunções do sistema musculoesquelético nestes trabalhadores.
\end{abstract}

Descritores: Sistema Musculoesquelético; Músico; Saúde do Trabalhador 